\title{
Adults versus teenagers: a false dilemma and a dangerous choice
}

The world has a compelling interest in reducing the morbidity and mortality caused by tobacco use. The question is not whether society should try to prevent the death toll from tobacco use, but rather how this objective can best be achieved. The answer is not simple given the complex relationship between the state of scientific knowledge (what we know about what is and is not effective in reducing tobacco use) and the capacity and will of government and society to adopt and implement the most effective strategies.

There is no dispute that, in the long run, public health efforts must seek to reduce tobacco use by young people and adults. However, there is an intense debate about what to do in the short run-focus exclusively on reducing adult tobacco use or focus on preventing children from starting. There are those who argue that programmes should not seek to reduce the number of children who use tobacco. They argue that these programmes are doomed to failure, do not work, and divert needed resources from those that do. They also argue that youth-oriented programmes are actually harmful because they inevitably bolster the tobacco industry's goal of creating the impression that, although it is wrong for children to use tobacco, there is no reason to discourage adults from doing so.

The premise of this article is that it is a mistake to allow the public health policy choice to be framed as whether to focus on adults or on children. The very debate assumes that a choice must or can acceptably be made, and that real progress can be attained by focusing on one, but not the other. Both assumptions are false. The push to frame the policy as an either/or choicewhether made by the tobacco industry, politicians or tobacco control advocatesshould be rejected.

An effective public health effort to reduce the death toll from tobacco should cut across age lines from the very beginning. The problem of tobacco affects people of all ages and society as a whole. Effective solutions must do so as well. An effective programme must seek to encourage adults to quit. But, it should not ignore the reality that virtually all new tobacco users are children.

Public health advocates must recognise that more can be done to cut off the tobacco industry's new supply of victims. There is really no conflict between the desire to reduce tobacco use among children and adults if programmes are properly designed. Those who argue that it is impossible to conduct a prevention campaign aimed at young people, without falling prey to the tobacco industry's trap, confuse the "target" and "goals" of the campaign with the campaign's "messages" and "tactics". The reality is that the themes and tactics that are the cornerstone of an effort to reduce tobacco use among children are most effective when programmes are designed with both adults and children in mind.

The reasons for including adults in any meaningful effort to reduce the death toll from tobacco are obvious. Despite all of the rhetoric about the concern of protecting children, the tobacco control movement has had its greatest success with adults and its most significant disappointments with children and adolescents. In the United States, for example, the prevalence of smoking has declined from over $40 \%$ of the adult population in 1965 to approximately $25 \%$ in $1995 .^{1}$

Although the decline in adult tobacco use has slowed in recent years in many developed nations, more can be accomplished. In 1989, California introduced a comprehensive tobacco prevention programme funded by an increase in its tobacco excise tax. From 1988 to 1996 adult smoking in California declined from $26.7 \%$ to $18.1 \%$, a decline of $38 \%$ or over twice the rate in the rest of the country. ${ }^{2}$ Since Massachusetts initiated a new comprehensive tobacco prevention programme in 1993, tobacco consumption has declined by $31 \%$ or four times the decrease in the rest of country excluding California. ${ }^{3}$ In Oregon, a programme begun in 1996 produced an $11.3 \%$ decline in tobacco use with about half of the decline attributed to a tax increase and half attributed to non-price measures. ${ }^{4}$

Therefore, the case for a continued emphasis on adults is plain. What about the arguments for and against an emphasis on children? There are compelling reasons for attempting to cut the number of young people who start. Despite the progress that has been made in encouraging and assisting adults to quit, overall consumption remains unacceptably high. The unfortunate reality is that the tobacco industry has been almost as successful at encouraging young people to start as public health advocates have been in encouraging adults to quit.

The experience in the United States is typical: it has been estimated that over 3000 young people become regular smokers every day. ${ }^{5}$ David Kessler, former commissioner of the United States Food and Drug Administration was correct when he labelled tobacco use a "paediatric disease"-not because it is wrong for children to smoke, but good for adults to do so-but because nearly $90 \%$ of all tobacco users start as children. There is good reason to believe that few will start as adults if more can be prevented from starting as children. 
The tobacco industry has long recognised that young people are the lifeblood of its future and has devoted considerable resources to research on children and to implementing marketing practices, which make tobacco products attractive and more accessible to children. With almost as many people becoming new, regular tobacco users every day as those who quit, an effort to make a fundamental change in the number of people who die from using tobacco cannot afford to ignore prevention.

The promotion of programmes designed to reduce tobacco use among children, and efforts to restrict the tobacco industry's actions that have a substantial impact on young people, also enhance the overall effort to increase the visibility and importance of tobacco as a public health issue. Rightly or wrongly, adults are assumed to be able to take care of themselves. No matter how egregious the behaviour of the tobacco industry, the public is less outraged when the victims are adults rather than children.

Even those politicians who agree that the public health goal must be to reduce tobacco use among adults as well as children are far more sympathetic and willing to take strong action to protect children. Politicians recognise that programmes to protect children are popular whereas those that appear to intrude into decisions made by adults are often seen as overly intrusive and may be politically risky. Thus, programmes that highlight the impact of the tobacco industry's actions on children heighten public concern about tobacco and increase the willingness of government officials and civic leaders to act.

The primary concerns voiced by public health advocates about programmes targeting young people is that they divert resources and energy away from programmes that have been proven to work and necessarily imply an acceptance of tobacco use among adults. This fear does not stand up to scrutiny. The tobacco industry would like to frame the debate about tobacco use as being about the lack of maturity of children to make wise decisions, implying if not stating that tobacco use among adults is a perfectly healthy, rational, and free choice that society should not try to discourage. It also implies that there is nothing amiss about an industry that continues to sell and actively promote a product which it knows kills and addicts, as well as doing nothing to effectively curtail the product's impact. But only the tobacco industry and a small number of politicians contend that the sole focus of any programme should be on children or contain only messages specific to young people.

Contrary to the impression left by some who advocate for an exclusive focus on adult tobacco use, no serious public health advocates have fallen into the tobacco industry's trap.

Indeed, virtually every public health expert agrees that the tobacco prevention programmes that have been effective with children have been careful to portray the reasons why one should not use tobacco as applying equally to adults and children. Indeed, those who sup- port programmes to reduce the number of children who start, agree that any effective programme must educate about the health effects of tobacco, de-glamorise tobacco use, expose the tobacco industry's wrongdoing, and help to foster an environment in which tobacco use is not the norm. It must also recognise that efforts to discourage young people from starting will be more successful if fewer adults smoke.

The second reason often given for an adultonly focus is the claim that programmes to reduce tobacco use among children and adolescents have been and continue to be doomed to failure.

It is the view of those who support a continued effort to reduce tobacco use among young people that, although tobacco prevention efforts in the past have often failed, there is now substantial, scientific evidence to support the conclusion that it is possible to reduce significantly the number of young people who start. Earlier this year the state of Florida reported that in only one year, a well-funded, comprehensive tobacco prevention programme reduced overall tobacco use among middleschool students by $19 \%$ and among high-school students by $8 \% .^{6}$ Although the results from California and Massachusetts have not produced a dramatic decline in overall consumption among children, these programmes did have a powerful positive effect. Tobacco use among children in the United States skyrocketed between 1991 and 1997. Not only did the California and Massachusetts programmes succeed in preventing this increase among children in their states, ${ }^{7-9}$ the data to date among middle-school students in Massachusetts indicates that tobacco use rates are in fact falling among this important cohort. $^{9}$

A growing body of evidence also provides support for the key individual components of programmes that seek to influence children. Controlled studies in New York and Vermont and elsewhere have documented the effectiveness of combining well-run, school-based programmes with simultaneously run mass-media programmes. ${ }^{10}{ }^{11}$ Significantly, these programmes have succeeded in changing attitudes and behaviour among adolescents. Similarly, there is a parallel, increasing body of evidence that well-run, scientifically validated programmes in schools can make a difference, particularly when they are combined with community-based efforts. ${ }^{12}$ These studies add scientific validity to the experiences in Florida and Massachusetts.

Thus, it is wrong to conclude that tobacco prevention programmes don't work. Although we have much to learn about how to maximise the effectiveness of these programmes, the data are now clear that comprehensive, welldesigned tobacco prevention programmes can reduce tobacco use among children.

The axiom that it is cheaper and easier to prevent disease than to cure it is equally true with tobacco. As long as the tobacco industry is able to generate a new smoker for every tobacco user it loses, tobacco control goals will 
remain elusive. If the public health community decides that it must choose between programmes aimed at young people or adults, the only winner will be the tobacco industry.

National Center for Tobacco-Free Kids,

MATTHEW L MYERS

1707 L Street, NW, Suite 800,

Washington, DC 20036, USA;

mmyers@tobaccofreekids.org

1 US Centers for Disease Control and Prevention. Cigarette smoking among adults-United States, 1995. MMWR 1997;46:1217-20.

2 Anon. California's tobacco control program: preventing tobacco related disease and death. Sacramento, California: Tobacco Control Section, California Department of Health Services, 3 Apr 1998 .

3 Abt Associates. Independent evaluation of the Massachusetts tobacco control program. Fourth annual report, fanuary 1994 to Fune 1997. Boston, Massachusetts: Department of Pubto fune 1997. Bo

4 US Centers for Disease Control and Prevention. Decline in cigarette consumption following implementation of a comprehensive tobacco prevention and education program-Oregon, 1996-1998. MMWR 1999;48:140-3.
5 US Centers for Disease Control and Prevention. Incidence of initiation of cigarette smoking-United States, 1965of initiation of cigarette smoking

6 US Centers for Disease Control and Prevention. Tobacco use among middle and high school students-Florida, 1998 and 1999. MMWR 1999;48:248-53.

7 Pierce JP, Gilpin EA, Emery SL, et al. Tobacco control in California: who's winning the war? An evaluation of the tobacco control program, 1989-1996. La Jolla, California: University of California, San Diego, 1998.

8 Independent Evaluation Consortium. Final report of the independent evaluation of the California tobacco prevention and education program: wave 1 data, 1996-1997. Rockville, Maryland: Gallup Organization, 1998.

9 Briton NJ, Clark TW, Baker AK, et al. Adolescent tobacco use in Massachusetts: trends among public school students, 1984-1996. Boston, Massachusetts: Health and Addictions Research, 1997.

10 Flynn BS, Worden JK, Secker-Walker RH, et al. Prevention of cigarette smoking through mass-media intervention and school programs. Am f Public Health 1992;82:827-34.

11 Flynn BS, Worden JK, Secker-Walker RH, et al. Mass media and school interventions for cigarette smoking prevention: effects two years after completion. Am $\mathcal{f}$ Public Health $1994: 84: 1148-50$

12 Pentz MA, et al. Longitudinal effects of the Midwestern Prevention Project on regular an experimental smoking in adolescents. Prev Med 1989;18:304-21.

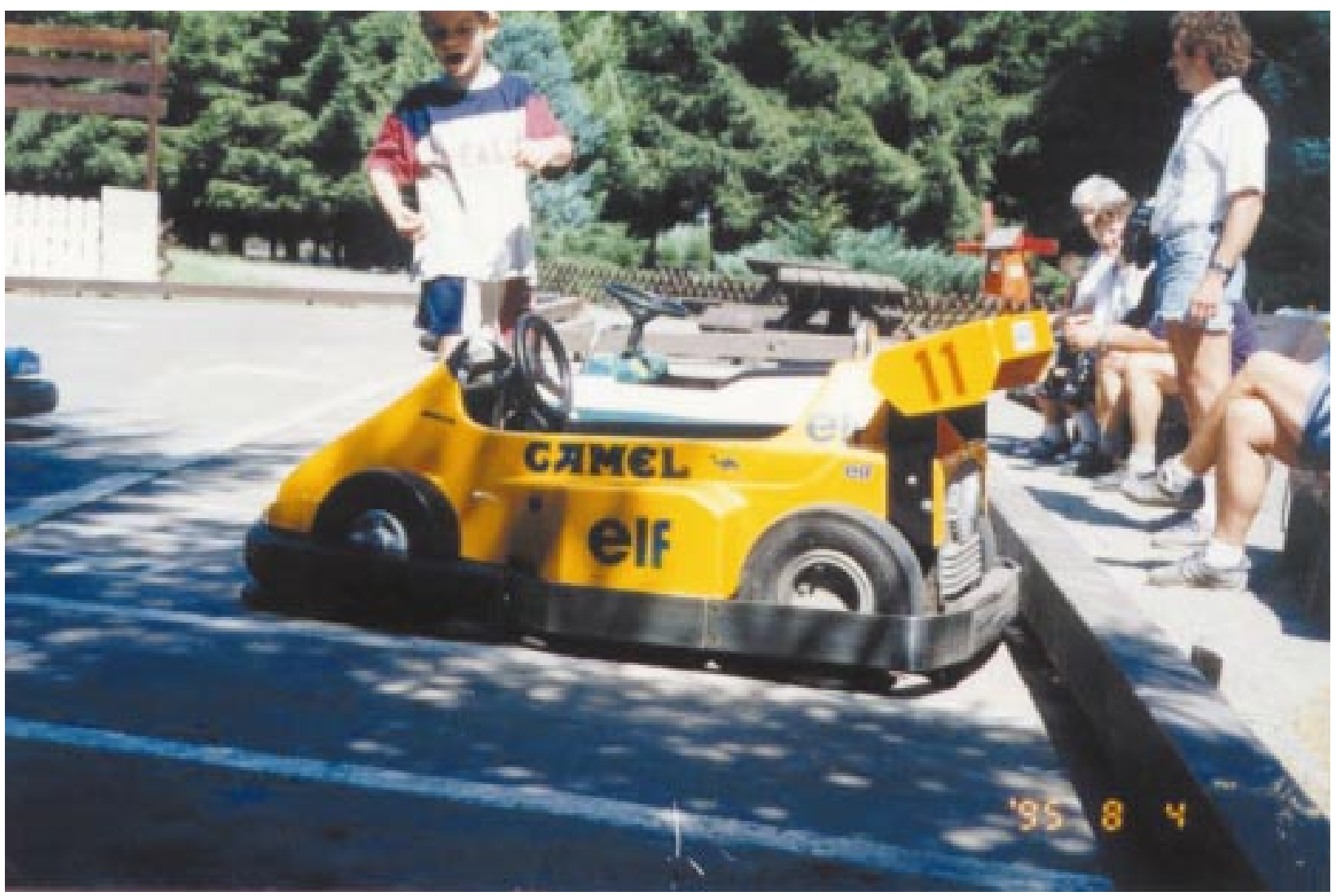

Adult-sized amusement park car with absolutely no appeal to children. Sababurg Tiergarten, Germany. Photo credit: Darlene Bahrs, San Francisco, California, USA. 